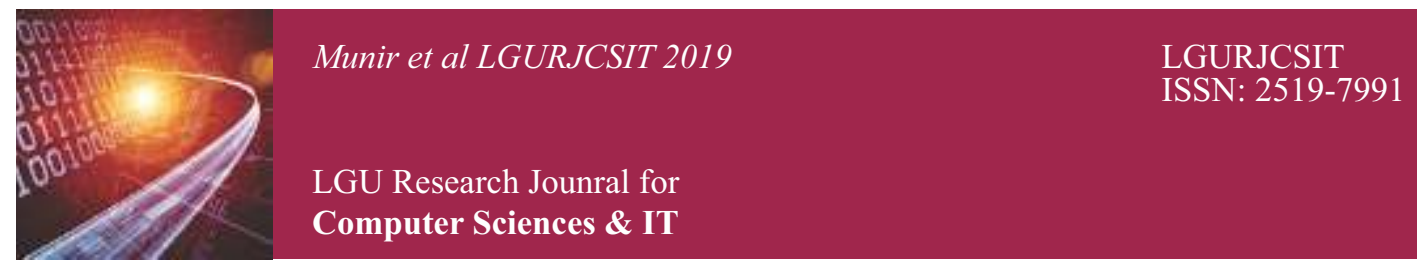

\title{
Cyberbullying in Individuals: Implications for Psychological Health
}

Sundus Munir ${ }^{1}$, Iqra Ashraf ${ }^{2}$, Abdul Waheed ${ }^{3}$, Afrozah Nadeem ${ }^{4}$

Department of Computer Science, Lahore Garrison University, Lahore, Pakistan

sundusmunir@lgu.edu.pk,, Iqra0379@gmail.com, ${ }^{2}$ waheedsj0001@gmail.com, ${ }^{3}$ afxnadeem@gmail.com ${ }^{4}$

\begin{abstract}
:
The aim of this research article and survey is to acknowledge the modern term of bullying, and develop better understanding of it by accessing all facts and causes of this problem. The effects of cyberbullying are directly proportional to effects of face to face bullying. Cyberbullying is negativity and aggressive behaviors that is often generated in a person's mind, it's traumatically effecting the psyches of adolescents and adults too. It also negatively effects the development of children, their academic performance, physical and mental health. Cyberbullying is a worldwide problem and many countries are experiencing its consequences. Cyberbullying has various impacts, and causes on one's health, so many services are provided by service providers such as physicians, nurses, parents and social workers. The objective is to educate parents, society and adults about symptoms of cyberbullying in victim as well as prevention and controlling over this problem. This paper includes consequences of cyberbullying on both victim's and bully's psyches. A survey has been conducted and its results are also included in this paper which shows the awareness rates, online bullying percentages and also other related factors that arises from cyberbullying.
\end{abstract}

Key Words: Cyberbullying, Adolescent, Aggressive Behaviors, Traumatically, Psyches, Services Providers

\section{INTRODUCTION}

Cyberbullying is when somebody harass or hurt someone emotionally by means of electronic social media. Online harassment includes teasing, taunting, threatening, false name calling, offensive comments, unpleasant pictures posting and sexual remarks. It can occur through different devices like cell phones, computers, tablets and medium used for this purpose is internet, SMS, calls, online chat rooms, online games and social media applications such as Facebook, Instagram, Twitter etc. [1] [2]. As we know now a day's internet is becoming a huge source of communication: new and efficient applications have been introduced for many years. People spend more of their time on these applications by connecting to internet and bullying other people. Cyberbullying is as much same as bullying face to face and its effects could be more likely to be same. Cyberbullying has various forms which are:

I. Harassment is known as Sending threatening and abusing messages to anyone.

ii. Online Exclusion is bitterly getting a person out of an online group, such as on Facebook groups, a chat line or in a game, it is also when a group of bullies stand up against a victim.

iii. Cyberstalking is transmission of threats, abuses or intimidation.

iv. Flaming is passing on vulgar and annoying messages.

v. Denigration is defaming by spreading cruel rumors about persons. It also includes treating a victim like he/she is useless.

vi. Masquerading is when some unauthorized person pretends to be someone else and shares information to damage a person's reputation.

vii. Outing is revealing secret of a person 
which was told in intimacy [2].

From the last few decades the use of internet and social media on mobile phones is a big cause of cyberbullying. According to a survey $44 \%$ of young people and children spent more than 3 hours per day on social media and 1 of $10(9 \%)$ uses social media at midnight [3]. According to analysis done by Global Digital Suite in 2018, the number of mobile users is 5.135 billion, number of internet world wide web's users is 4.021 billion and social media users are 3.196 billion [4]. Facebook becomes the most favorite and mostly used social media site in 2018 in all over the world. Approximately $87 \%$ being targeted of cyberbullying on Facebook and become victims [5]. There are 2.27 billion monthly active Facebook users according to statistics recorded in November, 2018 [6]. Most common age group of users on Facebook is $24-34$ years in which $80 \%$ of young boys and girls are using the social sites and most of them are female. According to an analysis 83 million fake profiles are on it. People post their photos, daily activities, videos on social media. These posts are total 300 million in a day means every 60 seconds on Facebook [7].In a careful measure average 510,000 comments are posted, 293,000 statuses are updated, and 136,000 photos are uploaded in a day [7]. This average percentage includes the users of all age group but $90 \%$ teens are most likely involved in bullying or being bullied online. 1 of 4 teenager agrees that he/she have been bullied on social media [8].

Cyberbullying have various forms like posting rumors, victim's random damaging pictures or posting personal information without permission. Many of them do this just for the sake of fun. Females mostly become victim of cyberbullying because they are easy to be tapped. Blackmailers uses different social media to trap female by flattering. Female believe on them and send their private pictures and personal information. After that they use that material to black mail them. Posting negative material about a person can ruin his/her private life because all activities are being stored on internet. There's record of every single click we do on internet and the record can be easily accessible. Bad posts about any individual can be harmful for their reputation; if any colleague, student, class mate or family member see that [9]. Cyber bullies can also affect the psychological health of victims. It can leave bad impact on the psyche and can be a serious cause of psychological health issue [10].

\section{Cyberbullying: A Worldwide Problem}

Cyberbullying is a huge worldwide problem. A study by Ipsos for Reuters News in which a survey including 24 countries show that $80 \%$ people in different countries say that cyberbullying is a problem, 19\% teenagers are bullying others online, $35 \%$ kids are being threatened online, $43 \%$ kids bullying others online and $58 \%$ adolescents do not talk to their parents about being bullied [6] [7]. Cyberbullying is more appealing than bullying offline because it can be done secretly and anonymously without revealing identity. People are criticizing each other not only face to face but also internationally by using internet. People who have never even met each other in real life are harassing each other on internet. Online bullying between the people of different countries, is producing racism. Cyberbullying is spreading hate between people of different countries and they are getting negative views in their minds. Creating awareness about cyberbullying in people is a need of this era. The highest awareness of this term is in Sweden and Italy which is $91 \%$ each, lowest awareness is $37 \%$ in Saudi Arabia. Similarly, in US, awareness level is relatively changed from $82 \%$ to $85 \%$ now [11]. Cyberbullying is also harmful for the reputation of countries.

\subsection{Internet Access: A factor of Cyberbullying}

According to research on the factors of cyberbullying, internet access is a main factor of this problem. The countries in which people have more internet access have this problem more than the countries which have less internet access. In china $57 \%$ people use inter- net, in India $40.10 \%$ users, USA has $76.18 \%$ users, in Africa 21.8\%, 70\% Americans and 43.9\% Pacific users have regular access to internet [6]. According to Internet World Stats, in Pakistan $22.2 \%$ of population have access to the internet [12]. Here a question arises how many people know about cyberbullying? The report of analysis shows that in Saudi Arabia 29\% people know, 87\% Australians, less than 50\% Chinese and $83 \%$ US citizens are aware of cyberbullying [11]. The Centers for Disease Control and 
Prevention surveyed and concluded that mostly young people in United States become a victim of cyberbullying. A survey has been done on the middle and high school students; survey resulted that; $20 \%$ of high school students are victims of cyberbullying, $16 \%$ students of middle school and $28 \%$ students of both high and middle school have been targeted through cyberbullying [11]. India is highest rated country in which most of cyberbullying cases are reported, 34\% parents reported that their children are being bullied online [13]. According to Digital Rights Foundation (DRF) in Pakistan, they received 535 calls about cyberbullying on Cyber Harassment Helpline and $41.3 \%$ cases were from Punjab as well as $62 \%$ calls were made by female victims [12].

The survey (2011-2018) by Ipsos international shows that how many parents have reported about cyberbullying. In India 37\% parents reported the problem, in Brazil 27\%, in US $26 \%$, in China $17 \%$ and Russia was in the bottom of list with $1 \%$ parents reported against cyberbullying. This survey also showed that cyber-bullying rates have increased in 2018 [11] [4] [6]. Hence this problem exists all over the world. Ethically and morally cyberbullying is a crime and it must be stopped because Cyberbullying results in low self-esteem, depression, anxiety, financial losses, damage of reputation and at the end even suicide [1]. Many youngsters have lost their precious lives due to this.

\section{Consequences and Causes of Cyberbullying}

Cyberbullying may not only harm victims physically but also mentally. It may also harm bullies as well. Effects of bullying can be significantly long-term or short- term, which will effectively harm victim's mental health as well as academic performances which may lead them to psychological disorder [14]. Psychological disorders include the development of negative affective disorders, anxiety, loneliness, depression, somatic disorder symptoms and ideation of suicide [15]. 93\% victims of cyberbullying reported negative effects, majority of victims reported that they feel loneliness, sadness, hopelessness and powerlessness [16]. According to Centers for Disease Control 4400 deaths per year occur, $14 \%$ teenager consider suicidal ideation and $7 \%$ average have attempted suicide [7]. There are so many suicides that have been attributed to face to face bullying as well as cyberbullying [17].

\subsection{Short-Term and Long-Term Effects on "Victim"}

In short term effects, victim emotionally becomes distressed, always feel angry, hopeless and sad under emotional distress. It lowers their self-esteem they always feel so much hatred around and think that no one likes them. They isolate them from socialization because of hatred they gathered from society and they think being around people may hurt them so they like to live alone. They lost believe in being loved and relationships, they indulge themselves in bad habits like smoking and drinking alcohol. They also lost interest in school assignments, extracurricular and productive activities. There eating and sleeping habits also changes so they are on high risk of illness. These victims are more prone to having most of behavioral problems. Threatening by bullies can harm victims in Long term effects, victims can harm themselves as well as others. It can lead them to do bad things in life such as a murder and suicide. Bullying can lead them to chronic depression, self-destructive behaviors and substance abuse [18] [19] [20].

\subsection{Short-Term and Long-Term Effects on "Bullies"}

Cyberbullying also harm the bullies. Like teenager bullies have the aggressive and teasing behavior. When they turn to age 24 , they are more likely to convict a serious crime. Bullies sometimes don't have any idea that how they are drawing themselves to destructive behavior which can harm their life in many aspects, bullies can also be a victim of other bullies and become a part of bullying [21]. Kid bullies can carry a relationship problem when they become an adult. Bullies also have a high risk of child and spousal abuse and problems with laws, because "say no to obeying" becomes a part of their psyches and they break law per law. They indulge themselves in bad habits like smoking, alcohol drinking, un-even sexual activities and they also cut off from religion.

Their psyches don't let them adjust in any environment and they may live uneducated or unemployed [19] [22] [18]. 
So, bullying never let anybody live happily. Its negative impact becomes the part of victim's and bully's psyches and harm them in several ways which are discussed above.

\subsection{Causes of cyberbullying: The Psychology of Being "Bully"}

Bullying online is done by two types of users socially active and socially non-active people. People who are socially active bully other users, because it makes them feel more powerful and popular. Socially in- active people also bully others because they want to be as powerful and popular as socially active people are [23].

Ditch the Label study conducted a survey and talked to 8,850 people about bullying. $14 \%$ said they have bullied someone. A comparison through questioning of both types of people's lives showed deficiencies in bullies' lives. Some factors which arise bullying are:

\section{i. $\quad$ Stress and Trauma}

The analysis showed that someone experiencing parents splitting, death of love ones, huge loss in life can lead them to stress and trauma can be a cause of bullying. Some people respond to stress in positive way by involving themselves in positive activities but some people respond in negative way indulging themselves in bad habits like teasing or bullying someone, substance abuse and alcohol consumption etc. They don't have any idea that they are getting themselves in long term problems.

\section{ii. Aggressive Behaviors}

Aggressive behavior can be caused when someone is trying to achieve one's social, psychological and physical needs. The deficiencies of these needs make people aggressive and they start bullying others whom they think are better than them. This is also noted that males are more aggressive than female because it is psyche of men to show that they are stronger and more powerful.

\section{iii. Low Self-Esteem:}

People who bully wants some attention because they have low self-esteem. It is a bitter truth of our society that some standards are set and everyone wants a perfect look despite knowing the factor, they look perfect as they are. People compares themselves to others, instead of embracing their own beauty and they bullied others to cover themselves behind masks.

\section{iv. They've Been Bullied}

The people who have experienced bullying are more likely to bully others. They might think that if they bully others, they will be immune to be bullied by someone. But the fact is, this bullying cycle creates more negativity in society.

\section{v. Difficulties in domestic Life}

Difficulties in domestic lives also make people aggressive, the children who don't get proper attention from home, financial and psychological difficulties in domestic life may indulge them in bad habits.

\section{vi. Low Access to Education:}

Without education, children don't learn the difference between good and bad. They don't know how to talk to people in an appropriate way. They talk to others aggressively and spread more hatred. This is also a cause of cyberbullying.

\section{vii. Having a Bad Company:}

Bad company of peers who bully other can be a cause of cyberbullying. Because bad company makes a person to do evil things. So, they also bully others online because of having a negative company [24] [25].

\section{The Important Role of Healthcare Providers}

Cyberbullying has its vital effects so many healthcare service providers including doctors, nurses, physicians, psychologists and social workers are struggling to prevent cyberbullying. Their aim is to educate people about bullying and accessing the problems that produce negative behaviors in children. Usually bullying habits grow in childhood so parents are the first who can identify the behavior of their children. The best way of preventing cyberbullying is to deal with it in first place by educating people about its consequences [26]. 
In the past few years, health care providers have played a more active role in preventing the long-term health consequences of cyberbullying. Research suggests that youth and parents are more willing to take care of a victim of cyberbullying. However, there is a difficulty, mostly youth do not disclose their experiences of being a victim when their parents are present there. They are ashamed of talking about this in front of their parents. However, many scholars argue that service providers should ask them about their involvement in cyberbullying [27].

Parents can teach their children about how to deal with it when aggression takes over them. They should tell them the difference between right and wrong. Also, the consequences they can face if they got caught involved in such activities. Parents should also create awareness in children about their rights and laws of cyberbullying. They must also recognize changes in children's behavior [28]. Common symptoms that show child is being abused or bullied are: difficulty in sleeping, stomach pain, heart pain, dizziness, bedwetting, destructive behaviors, lower self-esteem and lower school grades etc. [29].

\subsection{Control Efforts and Prevention of Cyberbullying}

To control cyber bullying many programs and prevention efforts have been introduced. Research on cyber bullying is a recent activity so the control efforts are also limited. Cyberbullying drew the attention towards this problem in 2010 when a 13 -yearold girl Megan Meier, a cyberbullying victim in US, hanged herself due to constant bullying about her weight [30]. Another 12-year-old New Jersey girl took her life because of being cyberbullied by her classmates [31].

Social and emotional learning (SEL) is the program of an organization named as CASEL (the Collaborative for Academic, Social, and Emotional Learning) which is located in Chicago, IL. Through this learning program, adults and children acquire knowledge and effectively apply that knowledge, skills and attitude to manage emotions. People set and achieve positive goals, establish and maintain positive relationships, feel and show empathy for others and become socially aware [32].

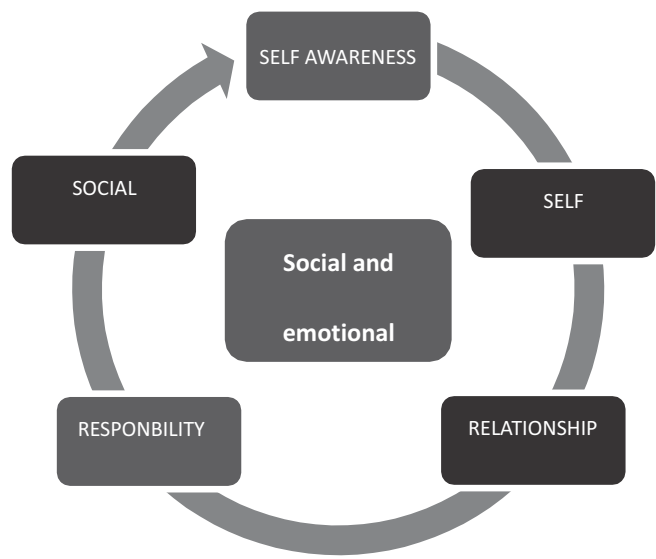

Fig1: Social and Emotional Learning (SEL)

SEL has been proved as an effective program. It has shown positive change in social emotional skills in las adolescent for last 20 years. These programs have shown positive results on psychological health, self-esteem and self- control and people wellbeing [27].

PREDEMA is the emotional education program which has been used effectively in prevention of short-term and long-term cyberbullying in adolescent. These programs used different theoretical approaches andmethodologies. This program effectively prevented the cybervictimization on mobile phones and internet [27].

\subsection{Preventing Cyberbullying through Websites and Tip Sheets}

Cyberbullying can be prevented if we educate people about its causes, circumstances and impacts on individual's life. So, a strategy is adopted by educating people through websites and tip sheets to provide information to teachers, students, parents and youngsters to avoid cybervictimization [39, 40]. Rebecca Ahlfors conducted a preliminary survey of 17 independent cyberbullying prevention websites to determine the general characteristics of these websites [33]. This survey concluded that 14 websites were designed to inform parents, in which 7 targeting young children (ages 6- 10 years), 8 were addressing tweens (ages 11-12 years), and 11 addressing adolescents (ages 1318 years). 9 websites were designed to address to school children and young people. 6 websites provide information about law but none of the websites provided information about service providers. Many scholars have also addressed 
some tips like do not read a message or content of cyberbullies, training of teachers and parents and making internet policies against cyberbullying [27].

Children Counselling services help children to create awareness of good and bad things. They motivate them to create positive behavior, they also can help cyberbullying victims by helping them and creating loving relationships [34].

Online help Services and digital help foundations also have been developed for children. If somebody is being bullied or harassed, they can report their complaint. Many websites have also been developed to help people e.g. stopbullying.gov and kidshealth.org etc [35].

In schools, there should be morale lectures for children's mind growth. Teachers must tell children about positive aspects of their behaviors, motivate them to adopt positivity. They must warn them about the consequences and punishment of being caught in bullying or in any other negative activity [13] [36].

There's an anonymity factor that lies in cyber bullying so there is a difficulty in identifying a bully online, besides $40 \%$ to $50 \%$ victims stated that they know their persecutor [37]. Schools faced these challenges to control cyberbullying, because cyberbullying is off school activity so it is so difficult to recognize a bully online, identity of a bully is anonymous and also victims are also reluctant to discuss about this to their parents [38].

\section{ASurvey: Methods and Results}

A survey is conducted for cyberbullying among 189 students in Pakistan on December 21,2018 . In this survey the target age group was 16-26 years old students, 120 students were female and 69 were male. This survey covers a range of public opinions, awareness, prevention and laws of cyberbullying. Aim of this survey was to analyze that how much awareness students have regarding cyberbullying. Mostly used media for cyberbullying, Social media usage per day, most used social media sites, number of people who have bullied online, number of people who have negative experiences on internet. Survey was done through questionnaire. In this questionnaire we gather information, analyze this information and calculate percentages. Our findings through this survey are as follows:

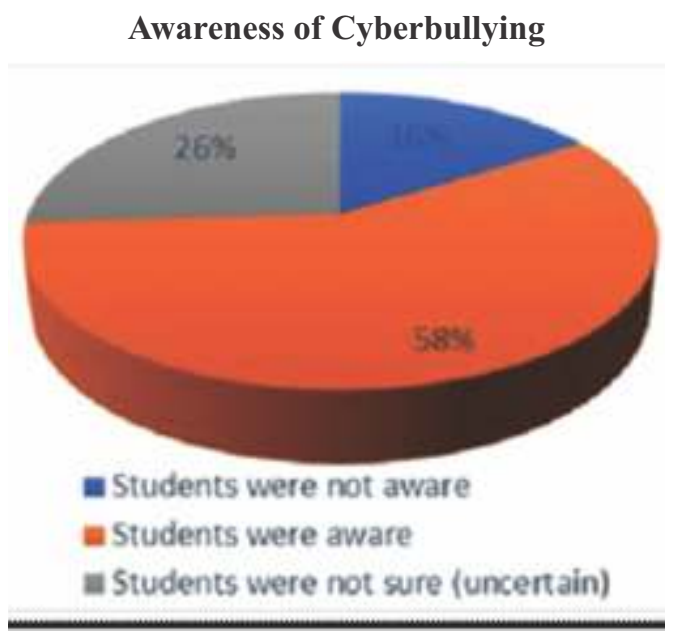

Fig 2: Cyberbullying Awareness Analysis

It is necessary to analyze that how much students know about cyberbullying. It is concluded that 35 students knew exactly what cyberbullying is, 11 students were uncertain and 17 students were not aware of cyberbullying.

Q. Are you aware on what to do if you're being bullied online?

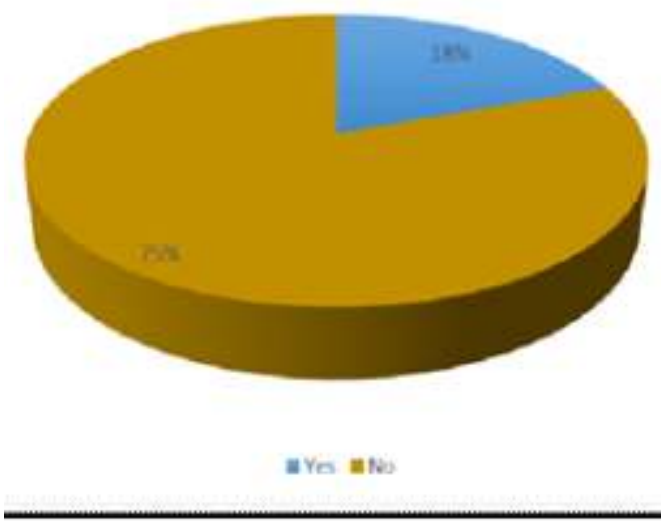

Fig 3: Online Bullied Awareness

It is very necessary for individuals, to know about their rights and obligations. If someone harass them, they should have to know that what should they do. 43 students say that they know about their rights and 20 students say that they don't know what should they do when they've been bullied online. 


\section{Social Media Usage per day}

Q. How often do you go on social media? i.e. Facebook, twitter, snapchat...Figure : Social Media Usage per Day

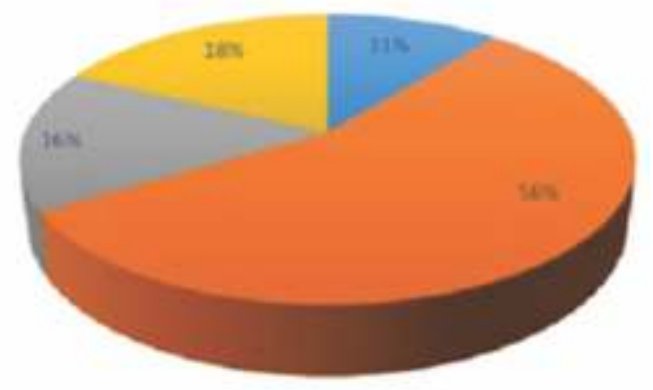

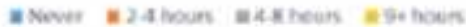

Fig 4: Social Media Usage per Day

Social Media usage is a huge factor of cyberbullying so; we analyze how often people use social media in a day. we analyzed that $56 \%$ students go on social media for $2-4$ hours, $11 \%$ students never used social media, and $18 \%$ say that they use social media $9+$ hours daily.

\section{Most used Social Media Sites}

Q. What social media sites do you use the MOST?

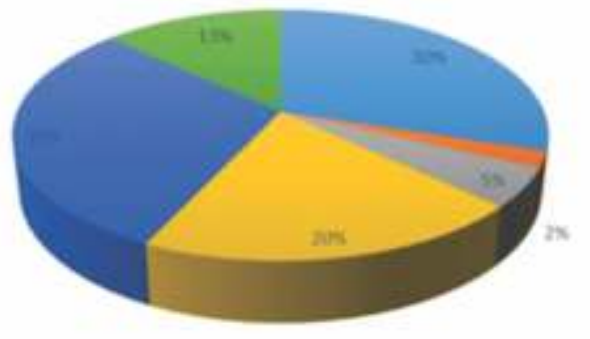

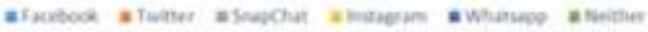

Fig 6: Most Used Media Sites

Mostly Social media site that is used for cyberbullying is Facebook. So, this question tells us about the favorite site of users. Therefore, it is noted that mostly used social media is Facebook. 30\% students say they use Facebook most. Number of people say they use WhatsApp, Facebook and Instagram simultaneously, twitter have lowest number of users. Similarly snapchat is also used by $4 \%$ people. Few students also say that they don't use any social media sites.

\section{Negative experiences on Social Media}

Q. Have you ever had any negative experiences with anyone on social media

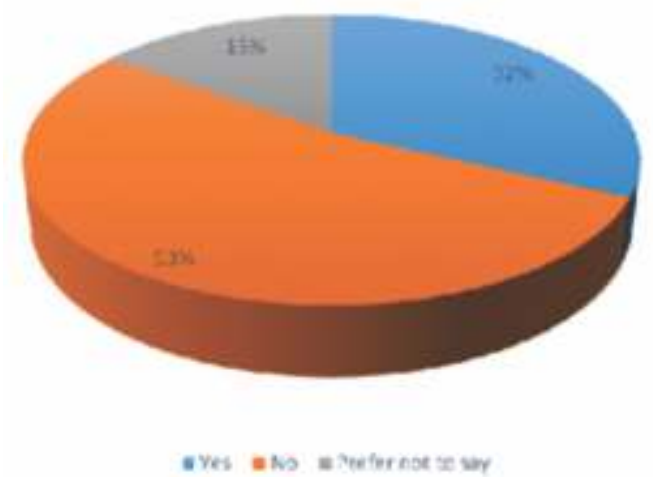

Fig 7: Negative Experience on Social Media

It is necessary to analyze how much society have been affected through cyberbullying. It is important because the severity of problem will tend to raise its effective solutions. $32 \%$ students had negative experiences with anyone on social media and 53\% says they never had any negative experience.

\section{How often cyberbullying happens}

Q. How often do you think cyberbullying happens?
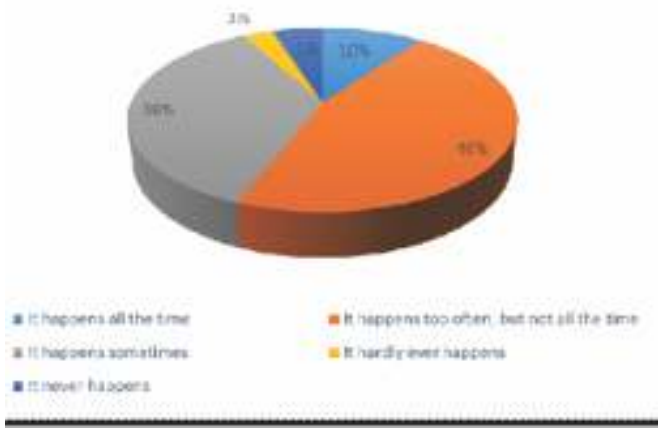

Fig 8: Happening of cyberbullying

Cyber bullying happens too often as we analyzed that $39 \%$ people said cyber bullying is a problem and it happens often but not all the 
time, $14 \%$ think that it never happens $21 \%$ were sure that it happens sometimes.

\section{Online Bullies}

Q. Do you know of anyone that has been bullied online?

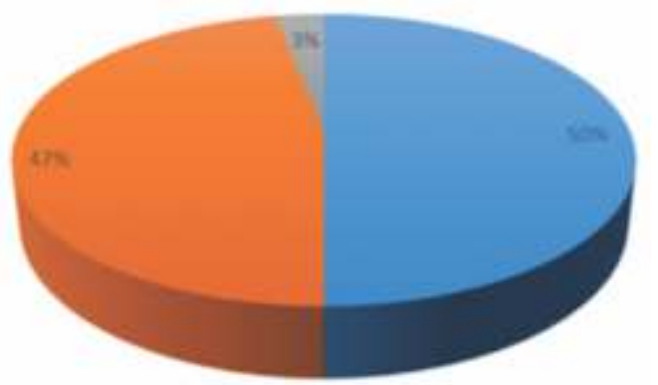

a Ves a No a Preher Not say

Fig 9: Online Bullies

Online Bullies are so difficult to identify because we cannot recognize them in cyberbullying as we can do in face to face bullying. We analyze that many Students know about cyber bullies. As survey shows 50\% students say that they know people who do cyberbullying. $47 \%$ say no and $3 \%$ don't want to talk about this.

Q. Have you ever been involved in any bullying online?

11 students say that they have been involved in online bullying and 45 students say that they never bullied anyone online.

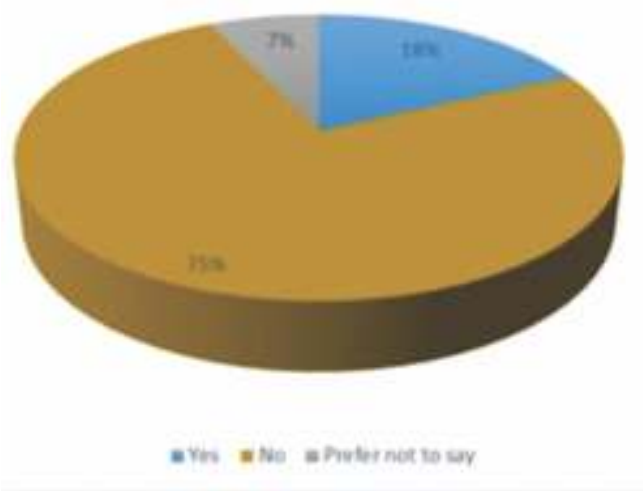

Fig 10: Involvement in Bullying

\section{Conclusion}

It is concluded that cyberbullying is the worst kind of bullying because on social media people get to live the way as they want. Most people don't even know them there, but if one gets bullied there too makes them feel that they don't belong there or they will never be able to fit anywhere in society which makes them highly sensitive and may also cause psychological problems. Cyberbullying is also a worldwide problem many countries are affected from this. From all around the world parents have reported that their children have been bullied online. Cyberbullying is affecting childhood of innocent children and destroying many societies, relationships and loving behaviors of people. There are some causes which make people aggressive and they start bullying others to overcome their aggression. Cyber bullying should be stopped, otherwise the world has to face its consequences. Many people have suffered due to this problem. Many children, adults have lost their consciousness and even lives. There is a long list of names of children and adults who have done suicide because of being bullied online and offline. Through a survey and research, it is analyzed that some more laws and cautions should be made to prevent cyberbullying. To use internet and technology one should follow strict policies and rules. Parents and teachers must guide children and should create awareness of good and bad deeds in them. They must warn them about the consequences they can face if they got caught in such activities.

There are few cautions and control efforts that have been taken in previous years. But some more practices need to stop this violation in society. Schools should have to help students who've been bullied online. Schools should show understudies how to avoid cyberbullying. Guardians ought to know about how to encourage their kids. There ought to be a helpline to encourage understudies. Additionally, a few meetings ought to be held for this.

Cyber bullying should be stopped because It can have severe effects on individuals to prevent this, there are some preventive measures: we should show our youngsters and understudies that harassing somebody is a most exceedingly bad thing and they don't need to do this. Similarly teach children to stand up to bullying in any way possible. Proper awareness 
sessions could be conducted to develop confidence in individuals. Parents should be aware of their children's outdoor, indoor activities and online activities. Teenagers should not be allowed to use internet without their parent's supervision. To make this world a better place to live for our upcoming generations, implementation of laws and policies must be done. There are many services, policies and laws to stop bullying but implementation on these policies will be more effective.

\section{References}

[1] C. L. Nixon, "Current perspectives: the impact of cyberbullying on adolescent health," 1 August 2014. [Online]. Available: https://www.ncbi.nlm.nih.gov/pmc/articles/PM C4126576/. [Accessed 14 December 2018].

[2] E. W. \&. R. M. K o w a $1 \mathrm{~s} \mathrm{k} \mathrm{i,}$ "Cyberbullying Via Social Media," Journal of School Violence, p. 20, 2015.

[3] E. N. A. \&. C. P. Menesini, " The measurement of cyberbullying: Dimensional structure and relative item severity and discrimination," Cyberpsychology, Behavior, and Social Networking, p. 14, 2011.

[4] Z. Villines, "Cyberbullying: A Global Trend," 22 May 2014. [Online]. Available: https://www.idgconnect.com/idgconnect/opini o n/1019831/cyberbullying-global-trend.

[5] D. X. Z. H. L. D. B. D. K. A. \&. E. L. Yin, "Detection of harassment on web 2.0. Proceedings of the Content Analysis in the WEB, 2.," 2009. [Online]. Available: http://www2009.eprints.org/255/6/Yin_etal_C Aw2009.pdf.

[6] S. COOK, "'Cyberbullying facts and statistics for 2016-2018," 12 November 2018. [Online]. A va i l a b l e : https://www.comparitech.com/internetproviders/cyberbullying-statistics/. [Accessed 14 December 2018].

[7] "The top 20 Valuable Facebook Statistics. [Online]. Available: https://zephoria.com/top-15-valuablefacebook-statistics/ [Accessed January 2019].
[8] F. sheet, "Comprehensive Review: Parents and Providers: Partnering with Healthcare Providers to Respond to Bullying," AbtAssociates, p. 2, 2017.

[9] P. W. Agatston, "Students' Perspectives on Cyber Bullying," Journal of Adolescent Health, p. 2, 2007.

[10] hendrickslavelle, "Cyber Bullying Among Teens," Journal of Bullying and Social Aggression, 1 November 2015. [Online].

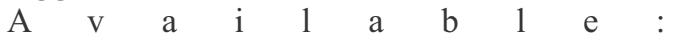
file://E:/Uni\%20work/7th/PP/article/cyber $\% 2$ 0 bullying/cyber-bullying-among-teens.html. [Accessed 14 Dec 2018].

[11] M. Newall, "Global Views on Cyberbullying," 27 June 2018. [Online]. Available: https://www.ipsos.com/en/globalviews- cyberbullying. [Accessed 22 Dec 2018].

[12] S. Zarar, "Punjab Has the Highest Number of Cyberbullying Cases: Report," $2016, "$ [O n lin e ]. Av a i l a b l e : https://propakistani.pk/2017/04/12/punjabhighest-number-cyberbullying-cases-digitalrights-foundation/. [Accessed 14 Dec 2018].

[13] C. S. B. M. R. Alex Chalk MP, "Safety Net: Cyberbullying's impact on young people's mental health,"YoungMinds, UK, 2017.

[14] K. Cherry, "A List of Psychological Disorders," 20 Nov 2018. [Online]. Available: https://www.verywellmind.com/a-list-ofpsychological-disorders-2794776. [Accessed 18 Dec 2018].

[15] I. K. a. K. Z.A., "Depression - A Review," Research Journal of Recent Sciences, p. 10, 2012.

[16] K. Hurley, "Short Term and Long Term Effects of Bullying," 26 September 2018. [On $1 \mathrm{ine}] . \quad A v$ a i l a b l e : https://www.psycom.net/effects-of- bullying. [Accessed 14 December 2018].

[17] Wikipedia, "List of suicides that have been attributed to bullying," [Online]. Available: https://en.wikipedia.org/wiki/List_of_suicides that_have_been_attributed_to_bullying. [Accessed 2018]. 
[18] H. Cowie, "Cyberbullying and its impact on young people's emotional health and wellbeing," The Psychiatrist, p. 4, 2013.

[19] R. Fraser-Thill, "The Effects of Being a Bully Children Who Are Bullies Face Increased Risks Throughout Life," 16 Sep 2018. [Online]. A $\quad$ v a $\quad$ i 1 a https://www.verywellfamily.com/the-effectsof-being-a-bully-3288472. [Accessed 16 Dec 2018].

[20] A. Research, "Cyberbullying Can Lead to Substance Abuse, Mental Health Issues," 1 July 2013 . [Online]. Available: https://www.recoveryranch.com/articles/addict $\mathrm{i}$ on-research/cyberbullying-can-lead-tosubstance-abuse-mental-health-issues/. [Accessed 14 Dec 2018].

[21] R. \&. V. V. T. Rafferty, "I hate everything about you": A qualitative examination of cyberbullying and on-line aggression in a college sample," p. 35, 2014.

[22] P. R. F. P. a. F. M. P. Tracy Vaillancourt, "Cyberbullying in Children and Youth: Implications for Health and Clinical Practice," The Canadian Journal of Psychiatry, vol. 62(6), p. 6, 2017.

[23] G. Gabriel, "What are the Causes of Cyber Bullying?," English Departement, 2017. [O n l ine ]. Ava i lable: https://english.binus.ac.id/2015/06/22/whatare-the-causes-of-cyber-bullying/. [Accessed 22 Dec 2018].

[24] D. T. LABEL, "Why Do People Bully? The Scientific Reasons," 14 Nov 2018. [Online]. Available: https://www.ditchthelabel.org/why-

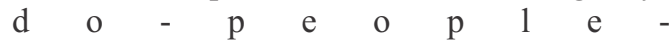
bully/?gclid=Cj0KCQiA05zhBRCMARIsACK DWjd79fuu 7jgUFr39gefuDL69jW4vtVOi7Zf E I91jF7DDU966rIfo0WIaAvtaEALw_wcB. [Accessed 29 December 2018].

[25] K. S. R. K. Bisla Preeti1, "Study of Depression, Anxiety and Stress Among School Going Adolescents," Indian Journal of Psychiatric Social Work, p. 4, 2017.

[26] Fact sheet, Comprehensive Review: Parents and Providers: Partnering with Healthcare Providers to Respond to Bullying,
Abt Associates, 2017.

[27] P. a. a. J. S. H. P. Dorothy L. Espelage, "Cyberbullying Prevention and Intervention Efforts: Current Knowledge and Future Directions," June 2017.

[28] Darrin, "The Psychological Effects of Cyber Bullying," 4 July 2017. [Online]. Available: https://pvteyes.com/thepsychological-effects- of-cyber-bullying/. [Accessed 14 December 2018].

[29] C. J. Psychiatry, "The Role of Health Care Providers in Cyberbullying," Canadian Journal of Psychiatry, 2017.

[30] T. N. Y. Times., "Megan Meier," 2009. [Online]. Available: https://www.nytimes.com/topic/person/meganmeier.

[31] M. Grossman, "Cyberbullying Tragedy: New Jersey Family to Sue After 12-Year-Old Daughter's Suicide," 1 August 2017. [Online]. Available: https://www.nbcnews.com/news/usnews/new-jersey-family-sue-school-districtafter-12-year-old-n788506. [Accessed 29 December 2018].

[32] S. a. E. L. (. Collaborative for Academic, "What is SEL?," CASEL, [Online]. Available: https://casel.org/what-is-sel/. [Accessed 2018].

[33] R. Ahlfors, "Many Sources, One Theme: Analysis of Cyberbullying Prevention and Intervention Websites," Journal of Social Sciences, vol. 6(4), p. 8, 2010.

[34] F. Wikipedia, "Cyberbullying," 8 Nov 2018 . [On line]. Available: https://en.wikipedia.org/wiki/Cyberbullying. [Accessed 17 Dec 2018].

[35] "Cyberbullying: What Parents, Providers Should Know," Massachusetts General Hospital, 24, May 2011. [Online]. Available:https://www.massgeneral.org/childre n/news/ne wsarticle. aspx?id=2960. [Accessed 25 December 2018].

[36] StopBullying.gov, "Warning Signs for Bullying," [Online]. Available: https://www.stopbullying.gov/at-risk/warningsigns/index.html. 
[37] E. Peebles, "Cyberbullying: Hiding Behind the screen," p. December, 2014.

[38] a. T. V. Megan A. Moreno, "The Role of Health Care Providers in Cyberbullying," 31 May 2017.
[39] http://www.stopbullying.gov/cyberbul lying/index.html;

[40] http://www.cyberbullying.ca/; http://www.prevnet.ca/ 